Revista de Economia Política, vol. 31, $n^{\circ} 3$ (123), pp. 397-414, julho-setembro/2011

\title{
Bancos públicos em sistemas financeiros maduros: perspectivas teóricas e desafios para os países em desenvolvimento
}

JENNIFER HERMANN*

Public banks in nature financial systens.

The paper discusses two theoretical approaches to the role of public banks (PBs): the Shaw-McKinnon model and an alternative Keynesian view. In the former, the PBs still in operation in less developing countries would be near to become fully unnecessary, in view of the advance of their financial development in the last twenty years. In the Keynesian approach this hypothesis is unlikely. Financial markets are viewed as structurally inefficient and "incomplete" for the requirements of the process of economic development. Nevertheless, it is undeniable that economic and financial development will require a definition of new strategies for PBs. The paper is concluded with a brief discussion of this issue.

Keywords: economic development; financial development; governmental banks. JEL classification: O16; G28; H81.

Como "braços financeiros" de políticas voltadas para o desenvolvimento econômico e social, Banco Públicos (BPs) são instituições idiossincráticas, cujo papel se define, a cada governo e período histórico, pelo que se entende serem as necessidades e limitações desse processo. A despeito da heterogeneidade de formas de operação, ditada por essa condição, um aspecto comum aos BPs é o fato de terem iniciado suas operações em mercados financeiros "incompletos", isto é, marcados pela inexistência ou grave insuficiência de determinados segmentos de operação.

A atuação de BPs em mercados financeiros incompletos comporta, no plano teórico, pelo menos, duas interpretações. Na visão dominante a partir dos anos

\footnotetext{
* Professora-adjunta do Instituto de Economia da Universidade Federal do Rio de Janeiro. E-mail: jennifer@ie.ufrj.br. Submetido: Julho 2009; Aprovado: Novembro 2009.
} 
1970, fundada no conhecido modelo Shaw-McKinnon (Shaw, 1973; McKinnon, 1973), a precariedade das condições de financiamento nos países em desenvolvimento fora atribuída à política financeira neles praticada no pós-guerra, cujo principal objetivo era a expansão da oferta de crédito a baixos custos. Além da fixação de tetos para os juros do crédito privado, tal política envolvia, entre outras medidas, a atuação de BPs como provedores de crédito de longo prazo a setores considerados estratégicos para o desenvolvimento. Shaw e McKinnon a denominaram de "política de repressão financeira", por entenderem que seu efeito era reprimir, e não estimular, o desenvolvimento financeiro. Neste enfoque, portanto, BPs são vistos como parte da causa da incompletude dos mercados financeiros onde atuam. Daí a inclusão de programas de privatização, ou simples extinção, de BPs, entre as linhas de política de liberalização financeira recomendadas para estimular o desenvolvimento econômico e financeiro nos países em desenvolvimento.

Contudo, assim como um copo "meio cheio" pode ser igualmente entendido como "meio vazio", a presença de BPs em mercados incompletos dá margem a uma interpretação oposta à do modelo Shaw-McKinnon. Como os BPs foram criados para atuar em segmentos de mercado preteridos pelas instituições privadas, uma interpretação possível é a de que, em vez de parte do problema, os BPs sejam parte da sua solução. Neste enfoque alternativo, a criação e atuação de BPs justifica-se pela incompletude do mercado e do sistema financeiro - e não o contrário - e pelo reconhecimento da importância de sistemas financeiros razoavelmente desenvolvidos para o desenvolvimento econômico.

Tal interpretação, porém, não torna mais confortável ou facilmente compreensível a posição dos BPs nos países em desenvolvimento. Em tese, à medida que seus sistemas financeiros "amadurecem", expandindo e diversificando os instrumentos e instituições em operação, reduz-se seu grau de incompletude, colocando em xeque a própria razão de ser dos BPs. Essa expansão e diversificação de fato ocorreu em muitos países em desenvolvimento, especialmente a partir das políticas de liberalização financeira dos anos 1990 - embora não exatamente nos moldes "benignos" ao desenvolvimento econômico, previstos no modelo. ${ }^{1}$

Por outro lado, a existência de BPs atuantes em países do G-7 — Kredintaltanlt fur Weidarufban (KfW, na Alemanha), Development Bank of Japan, Japan Post Bank, Business Development Bank of Canada, entre outros, todos de capital 100\% governamental - cujos sistemas financeiros são inequivocamente desenvolvidos, parece contestar empiricamente aquela tese. No plano conjuntural, cabe mencionar ainda o reconhecimento, por parte do Fundo Monetário Internacional e de outros órgãos e analistas internacionais, de que as economias emergentes que contam com BPs atuantes - entre elas, o Brasil — têm sido menos atingidas que seus pares

\footnotetext{
${ }^{1}$ Hermann (2009), por exemplo, demonstra que, no Brasil, embora o sistema financeiro tenha se expandido e diversificado a partir dos anos 1990, o crescimento econômico não foi beneficiado neste processo.
} 
pela crise financeira internacional recente (2008-2009). Isto sugere a emergência de um novo papel para esses bancos na "era da liberalização".

Este artigo discute o papel de BPs no sistema financeiro, numa perspectiva teórica, a partir do confronto de dois enfoques alternativos: o modelo Shaw-McKinnon, de filiação neoclássica, e um enfoque keynesiano, aqui formulado a partir de teorias de filiação novo- e pós-keynesiana. Cabe advertir que não se tem a pretensão de formular uma "teoria econômica geral" dos BPs. A natureza híbrida desses bancos - simultaneamente, instituições políticas (formuladoras ou executoras de políticas de Estado) e instituições financeiras stricto-sensu - lhes confere um perfil pragmático, idiossincrático e, em grande parte, "datado", que dificulta imensamente essa tarefa. Além do apoio de abordagens do campo da história e da teoria política, no próprio campo da teoria econômica uma análise abrangente do papel dos BPs nos mercados e países onde atuam deveria ainda envolver aportes da teoria do desenvolvimento econômico. ${ }^{2}$ Tal análise, porém, foge aos objetivos deste artigo. O objetivo central da discussão aqui proposta é o de fornecer uma fundamentação teórica para a compreensão do papel dos BPs na função estrita de bancos, nos países em desenvolvimento com sistemas financeiros relativamente maduros, ou a caminho disso. Essa discussão mostra-se particularmente relevante para o Brasil, que, nesse bloco de países, ostenta um dos sistemas financeiros mais extensos (em número e tamanho das instituições) e diversificados.

$\mathrm{O}$ artigo consiste em mais três seções. A segunda seção introduz a discussão teórica proposta, tendo por foco o papel do Estado no mercado financeiro. A terceira seção estende essa discussão para a questão das formas de atuação do Estado nesse mercado, enfatizando a atuação através de BPs. A quarta seção conclui o artigo, utilizando o enfoque keynesiano como base para a formulação de uma interpretação sobre o papel de BPs em sistemas financeiros maduros de países em desenvolvimento.

\section{PAPEL DO ESTADO NO MERCADO FINANCEIRO}

\section{Papel versus formas de atuação do Estado no mercado financeiro}

Mesmo numa perspectiva teórica restrita à teoria financeira, o papel dos BPs não se define apenas pela extensão do desenvolvimento financeiro do país em questão, cujo avanço, medido pelo volume e diversificação dos negócios privados, determinaria, inversamente, o espaço de atuação desses bancos. Em face da inevitável dimensão política dos BPs, a discussão sobre seu papel na economia se confunde, em larga medida, com a discussão a respeito do papel do Estado no sistema financeiro. Esta se desenvolve a partir de dois grandes consensos:

\footnotetext{
${ }^{2}$ Para uma abordagem também apoiada em teorias do mercado financeiro e do desenvolvimento econômico, ver BNDES (2007).
} 
a) diversos estudos teóricos e empíricos apontam o desenvolvimento e "bom funcionamento" do mercado financeiro (aí incluídos o mercado bancário e o mercado de capitais) como importantes condicionantes do crescimento e do desenvolvimento econômico; ${ }^{3}$

b) o reconhecimento de que o setor financeiro é marcado pelo atributo da externalidade (geração de impactos positivos ou negativos em outros setores) forma certo consenso também quanto à necessidade de algum tipo de intervenção estatal no setor.

Contudo, o consenso desaparece quando se trata de definir a forma adequada de intervenção estatal. Há diversas formas de atuação possíveis, não mutuamente excludentes, que, numa escala ascendente de intervenção, podem envolver: a simples supervisão do mercado, operando com regras próprias (autorregulação supervisionada); a regulamentação do setor (que pode também assumir graus de intervenção variados); políticas de crédito direcionado a setores selecionados; políticas de desenvolvimento financeiro; parcerias com agentes financeiros privados na execução dessas políticas; e criação de BPs. Esta última, mais que a atuação do Estado no mercado financeiro, caracteriza uma forma de atuação no sistema financeiro, isto é, na estrutura de instituições que compõem o mercado.

Além da falta de consenso, a discussão sobre as formas de atuação do governo no sistema financeiro é ainda pouco desenvolvida e sistematizada. ${ }^{4} \mathrm{Em}$ geral, propostas neste sentido surgem como uma extensão, às vezes um tanto forçada, das conclusões sobre o papel do Estado no mercado financeiro. Essa questão, de fato, precede logicamente aquela discussão a respeito das formas de atuação, mas certamente não a esgota. Nesta seção abordam-se sequencialmente, as duas questões, sendo a discussão sobre o papel do Estado no mercado financeiro o fio condutor da análise dos fundamentos teóricos de sua atuação através da criação de BPs.

Duas abordagens polarizam hoje o debate a respeito do papel e formas de atuação do Estado no mercado financeiro: a) o modelo Shaw-McKinnon, que defende políticas de liberalização financeira e, portanto, uma atuação mínima e não intervencionista; b) o enfoque keynesiano, baseado em argumentos das escolas novo- e pós-keynesiana, que justificam uma atuação ampla do Estado no mercado financeiro.

\footnotetext{
${ }^{3}$ É extensa a lista de trabalhos sobre o tema. Uma amostra razoável dela é comentada em Hermann (2003). Entre os trabalhos mais importantes, cabe mencionar o artigo seminal de Gurley e Shaw (1955) e os livros de Shaw (1973) e McKinnon (1973). Além desses, ver ainda Zysman (1983), Levine (1997 e 2004), Stiglitz (1994 e 1998) e a série de artigos publicados em Dixon (1997).

${ }^{4}$ Para um sumário dessa discussão ver Panizza et al. (2004).
} 


\section{A visão Shaw-McKinnon ${ }^{5}$}

O modelo Shaw-McKinnon apoia-se em três proposições centrais: a) o financiamento do investimento e, portanto, do crescimento econômico, requer o acúmulo prévio de poupança; b) a poupança agregada é uma função positiva da taxa real de juros; c) mercados financeiros livres conduzem a taxa real de juros, a poupança agregada e a taxa de crescimento a seus níveis "ótimos". Como sintetizam Agénor e Montiel:

The McKinnon-Shaw argument is that a rise in interest rates on savings and deposits will increase the saving rate in developing countries and, in standard neoclassical fashion, raise the rate of economic growth. The increase in interest rates will lead to an inflow of deposits into commercial banks, raising their capacity to lend and finance investment. (Agénor e Montiel, 1999, p. 208-209)

As proposições (a) e (b) são aplicações, ao debate sobre desenvolvimento econômico, da conhecida teoria neoclássica da taxa de juros. A terceira sintetiza a "hipótese de mercados eficientes" (HME). Esta é o resultado da adaptação, ao mercado de ativos, de conceitos e hipóteses do paradigma neoclássico, originalmente formulados para os mercados de bens (Stiglitz, 1994; Ross, 1994): o conceito de eficiência de Pareto e as hipóteses de informação perfeita (ou sem custos), perfeita flexibilidade de preços e inexistência ou irrelevância de custos de transação.

Uma combinação de preços e quantidades é dita Pareto-eficiente se gera o máximo relativo da função-utilidade social do mercado em questão. Em um sistema eficiente, dados os fatores de produção, o nível de produto e bem-estar em qualquer mercado, bem como a posição de qualquer agente individual, não pode ser incrementado sem o sacrifício de outrem. As demais hipóteses são as condições necessárias para que um sistema ou mercado convirja para a eficiência de Pareto: a inexistência de custos de informação permite aos agentes econômicos conhecerem todas as condições e oportunidades do mercado, viabilizando a melhor escolha; as duas últimas viabilizam o alcance do equilíbrio do sistema através de mudanças nos preços e quantidades.

A aplicação do conceito de eficiência de Pareto ao mercado financeiro requer algumas adaptações. Como observa Ross (1994, p. 26):

In finance the word efficiency has taken on quite a different meaning. [...] The basic intuition of efficient markets is that individual traders process the information that is available to them and take positions in assets

\footnotetext{
${ }^{5}$ Para exposições detalhadas do modelo Shaw-McKinnon, ver, além dos trabalhos que lhe deram origem - Shaw (1973) e McKinnon (1973) - Fry (1995) e Agènor e Montiel (1999). Para análises críticas do modelo, ver Studart (1995-1996) e Hermann (2003).
} 
in response to their information as well as to their personal situations. The market price aggregates this diverse information and in that sense it "reflects" the available information. (aspas do original)

No mercado de ativos, o recurso escasso que limita o máximo relativo da função-utilidade não são os fatores de produção, mas sim a informação a respeito das condições de retorno e risco dos ativos. Neste mercado, portanto, o equivalente da alocação ótima de recursos que define a eficiência de Pareto no mercado de bens é a utilização plena e correta da informação disponível.

A HME tem implicações extremamente úteis para justificar a política financeira que deriva do modelo Shaw-McKinnon: a) em mercados livres, as taxas de juros serão, por definição, taxas de equilíbrio eficiente: a imposição de qualquer outra taxa de juros via política (de repressão) financeira resultará em um equilíbrio menos eficiente que o gerado pelo mercado; b) as taxas de mercado refletem corretamente os fundamentos micro- e macroeconômicos dos ativos e, assim, correspondem a taxas "justas"; c) quando as taxas se tornam "elevadas", desestimulando o investimento e o crescimento econômico, o meio certo de rebaixá-las não seria a imposição de tetos de juros ou a implementação de programas de crédito direcionado, mas sim políticas capazes de "melhorar" os fundamentos (reduzir os riscos de natureza macroeconômica e informacional) do referido ativo.

Por fim, no modelo Shaw-McKinnon não há distinção entre mecanismos de formação de taxas de retorno para ativos de curto e de longo prazo. Tal proposição é compatível com a ideia de que as taxas dos diferentes ativos, em equilíbrio, refletem diferenças entre seus graus de risco - que dependem, em parte dos prazos de maturação. Assim, tudo o que se requer para a formação de um mercado de ativos de longo prazo é que o mercado seja livre para refletir corretamente esses riscos. Shaw é explícito na defesa deste ponto:

[...] The repressed, lagging economies have nothing to gain by adding the paraphernalia of long-term finance to their financial systems. [...] Monetary reform, with deepening of money, is an indispensable first thing to do. (Shaw, 1973, pp. 144-145)

Nesse enfoque, naturalmente, não há espaço para políticas financeiras intervencionistas. A intervenção do governo é vista como desnecessária e deletéria: se confirma os preços de mercado, é redundante e, portanto, um desperdício de recursos públicos; se ocorre ou induz a preços distintos dos que seriam livremente praticados é uma distorção, que reduz a eficiência do mercado. O precário desenvolvimento de certos segmentos do mercado financeiro em alguns países, assim, não refletiria qualquer dificuldade intrínseca ao mercado, mas sim o resultado das políticas de "repressão financeira". 


\section{O enfoque novo-keynesiano}

A abordagem novo-keynesiana do mercado financeiro tem como principal foco de crítica ao modelo Shaw-McKinnon a validade da HME, substituída pela hipótese de falhas de mercado. Falhas de mercado são condições, transitórias ou permanentes, que impedem a operação "eficiente" do mercado, isto é, que os preços e volumes negociados se ajustem, refletindo, corretamente e em curto prazo, as informações relativas ao retorno e risco de cada ativo. Cinco tipos de falhas de mercado são normalmente apontadas (Stiglitz e Walsh, 2003, parte 3; Stiglitz, 1994 e 1998; BID, 2005, cap. 11): a) custos de transação; b) custos e assimetria de informação; c) externalidades positivas e negativas; d) mercados incompletos; e) concorrência imperfeita.

Os três primeiros tipos seriam inerentes ao mercado financeiro, constituindo, assim, justificativas teóricas para a intervenção do governo em graus variados. Os dois últimos seriam circunstanciais, podendo justificar esta intervenção em casos (países, períodos) específicos.

A inexistência (ou níveis desprezíveis) de custos de informação e de transação é uma condição requerida para que a operação do mercado financeiro se dê, sistematicamente, de forma "eficiente": somente neste caso os agentes poderiam ter acesso a todas as informações relevantes e incorporá-las rapidamente aos preços dos ativos através de operações de compra e venda. Contudo, tal condição seria incompatível com as funções básicas (e a razão de ser) do sistema financeiro: na ausência de custos de informação e transação, poupadores e investidores prefeririam sempre o financiamento direto, evitando, assim, o pagamento de rendas de intermediação ao sistema financeiro (Goodhart, 1989; Tobin, 1994). A existência e dimensão da atividade bancária nas economias de mercado seria, assim, uma prova empírica da existência regular desses custos no mercado financeiro.

Os custos de transação das operações financeiras (assim como de outras atividades econômicas) decorrem da necessidade de busca dos agentes por outros interessados em seu produto (recursos excedentes, no caso dos poupadores; títulos de dívida, no caso dos investidores) e dispostos a aceitar as condições (preços e prazos) oferecidas. A concentração de recursos em agentes intermediários reduz os custos de transação dessas operações, através da especialização e das economias de escala exploradas pelas instituições financeiras.

Os custos de informação derivam da condição de assimetria de informação que caracteriza as transações no mercado de ativos. $\mathrm{O}$ fato inevitável de que os devedores conhecem melhor sua real capacidade de pagamento que seus potenciais credores envolve um risco elevado e de difícil administração para o poupador não especializado, tendendo a limitar seu interesse pelas operações diretas no mercado de capitais. ${ }^{6}$ Nesse contexto, as instituições financeiras cumprem três importantes

\footnotetext{
${ }^{6}$ Como observa Stiglitz (1998, p. 3), em decorrência dos riscos da informação assimétrica, mesmo os mercados de capitais mais regulamentados e, supostamente, mais seguros (como o norte-americano,
} 
funções: a coleta de informação, a administração e a assunção dos riscos das operações de crédito. A especialização e a possibilidade de explorar economias de escala garantem, também neste caso, vantagens comparativas às instituições financeiras (ante os poupadores individuais). Em suma, o cumprimento dessas funções é o que justifica a apropriação de rendas de intermediação pelo setor financeiro. ${ }^{7}$

A atuação de instituições financeiras pode reduzir substancialmente os custos de transação para poupadores e investidores. Os custos e riscos associados à informação assimétrica, contudo, por derivarem de uma falha de mercado incontornável, não podem ser reduzidos a níveis desprezíveis, mas apenas transferidos às instituições financeiras. Dessa forma, mantém-se como permanentes geradores de ineficiência no mercado financeiro.

Devido à assimetria de informação, os bancos não podem distinguir, adequadamente, os diferentes graus de risco dos potenciais devedores, de modo a fixarem taxas de juros "justas" (eficientes) para cada projeto. Diante dessa limitação, fixam taxas homogêneas para projetos distintos quanto ao risco. Disto deriva uma primeira fonte de ineficiência: as taxas de juros dos diferentes ativos não refletem corretamente seus fundamentos microeconômicos. Em segundo lugar, como demonstram Stiglitz e Weiss (1981), a forma típica dos bancos reduzirem os riscos da assimetria de informação é a fixação de um "teto" para suas taxas de juros. Não sendo possível identificar cada risco, os bancos tendem a seguir dois critérios convencionais de avaliação: a) a maiores taxas de retorno correspondem maiores graus de risco (Tobin, 1958); b) a taxa de juros aceita pelo devedor é, simultaneamente, um indicador de suas expectativas de retorno e de sua propensão a riscos. Assim, a total incorporação do grau de risco estimado à taxa de juros tem eficácia limitada como meio de proteção do credor, ao contrário do que supõe o enfoque dos mercados eficientes: o aumento da taxa de juros, diante da expectativa de riscos maiores, resultaria na atração de devedores mais propensos a risco (efeito seleção adversa), elevando o risco total a que se expõe o banco e reduzindo o retorno ajustado.

Nessas condições, o custo e a oferta de crédito são determinados por um critério de risco máximo aceitável (Hermann, 2000). Este define a taxa de juros "ótima" para o banco - que maximiza o retorno ajustado ao risco - e, por meio desta, a oferta de crédito: até certo limite (inferior ao risco máximo) quanto maior o risco aceitável, maiores serão a taxa ótima de juros e a oferta de crédito. Assim, o teto de risco pode gerar um "equilíbrio" com racionamento de crédito, sempre que a demanda exceder a oferta máxima assim definida. Dessa forma, a ineficiência do mercado financeiro na fixação do custo do crédito se estende à alocação de recursos.

Pela mesma razão, pode-se esperar um comportamento pró-cíclico e, portanto, instabilizador, da propensão a riscos e da oferta de crédito dos bancos (Stiglitz,

citado pelo autor) mantêm-se em posição secundária como fonte de financiamento para as firmas, que, então, não podem prescindir de empréstimos bancários.

\footnotetext{
${ }^{7}$ As instituições depositárias cumprem ainda outra função essencial: a organização e operação do sistema de pagamentos da economia.
} 
1998, p. 7). Nas fases de maior crescimento econômico, os bancos (assim como outros agentes econômicos) tornam-se mais otimistas, expandindo o crédito e prolongando, talvez de forma indevida (ineficiente), a fase expansiva. Nas fases recessivas, os bancos tendem a ser mais cautelosos, racionando o crédito e agravando a tendência à retração econômica.

Outra fonte de ineficiência no mercado financeiro são as externalidades típicas de sua operação. As principais externalidades positivas decorrem de seus efeitos benéficos para o desenvolvimento econômico, viabilizando maiores taxas de investimento e, em certos casos, de produtividade, pelo financiamento (quando ocorre) de setores com efeito-encadeamento para a frente, como infraestrutura e inovações. No entanto, esses possíveis efeitos macroeconômicos não são suficientes - nem necessários - para induzir um banco privado a financiar um empreendimento. Nestes casos, o retorno social esperado (pela sociedade) é, provavelmente, maior que o retorno financeiro ajustado ao risco, estimado pelo banco, gerando um "equilíbrio" com racionamento de crédito.

Quanto às externalidades negativas do mercado financeiro, as usualmente apontadas são a possibilidade de geração de "bolhas" (valorização excessiva) de ativos, pela excessiva propensão a riscos dos agentes nas fases otimistas; de crises de crédito (forte e abrupta escassez), pela excessiva cautela nas fases pessimistas; ou de contágio entre segmentos e da economia em geral (risco sistêmico). Essas condições são, obviamente, geradoras de ineficiência macroeconômica.

Por fim, a incompletude do mercado financeiro e a concorrência imperfeita podem surgir como desdobramentos adicionais da presença de informação assimétrica e/ou de externalidades. Essas condições justificam a incompletude do mercado nos segmentos que envolvem maior dificuldade de avaliação e compensação de riscos - caso do mercado de capitais, do crédito de longo prazo em geral, do crédito para pequenas e médias empresas e do financiamento de P\&D e de investimentos em inovações. Quanto à concorrência, os elevados custos de informação representam uma espécie de "barreira à entrada", que torna a concorrência imperfeita uma tendência no mercado financeiro.

Em suma, a racionalidade e possível eficiência microeconômica das instituições financeiras diante dos custos e riscos da informação assimétrica não garantem a eficiência macroeconômica do mercado financeiro na alocação de recursos, tendendo, ao contrário, a reduzi-la. Isto justifica a atuação regular do Estado neste mercado, pelo menos na forma de regulamentação (e não apenas supervisão) e de políticas financeiras.

\section{O enfoque pós-keynesiano}

O enfoque pós-keynesiano guarda semelhanças com a abordagem das falhas de mercado, sendo, porém, mais radical na crítica à HME e mais pessimista quanto à possibilidade do mercado operar de forma funcional ao desenvolvimento econômico. Nessa visão, o principal entrave à eficiência do mercado financeiro (assim como de outros mercados) é a incerteza - e não apenas o risco decorrente da as- 
simetria de informação - que cerca, inevitavelmente, as decisões econômicas e, em particular, as operações financeiras.

O mercado financeiro produz e negocia direitos sobre renda futura. Estimativas de renda futura envolvem risco (probabilidade de eventos desfavoráveis), incerteza (eventos desconhecidos) e, em função desta, graus variados de confiança nos cenários formulados. O problema não se resume ao custo e acesso à informação, mas envolve também a inexistência dela: trata-se de informações sobre a evolução do mercado ao longo do período (futuro) durante o qual o ativo em questão pode ser retido em carteira ou renegociado. Nesse contexto, utilizar toda a informação disponível não é garantia de uma alocação de recursos eficiente, porque grande parte das informações necessárias ao cálculo do retorno do investimento são indisponíveis (Kregel, 1980).

A incerteza, ao contrário do risco, refere-se ao que, reconhecidamente, não pode ser previsto e, portanto, não pode ser precificado. O desenvolvimento de modelos estatísticos de previsão (necessariamente baseados em dados passados), operações de hedge (que compensam perdas previstas) ou a inclusão do risco previsto na taxa de retorno exigida são instrumentos relativamente eficazes para lidar com o risco, mas não com a incerteza.

Por outro lado, a incerteza não conduz também à inação, mas sim ao desenvolvimento de mecanismos de defesa: a) a fixação de contratos reduz a incerteza quanto à evolução dos preços e volumes em negociação durante o tempo de vigência do contrato - mas tal recurso só é eficaz até o ponto em que a incerteza não é forte o suficiente para inibir os contratos; b) mercados secundários permitem a revisão de decisões anteriores (embora não sem custos) - pela mesma razão, contudo, podem tornar-se também mais uma fonte de incerteza e risco, por gerar variações frequentes nos preços dos ativos; c) seguir mais a tendência do mercado que sua avaliação pessoal sobre determinado ativo - "comportamento convencional" (Keynes, 1985, cap. 12) — reduz a probabilidade do investidor incorrer em grandes perdas, decorrentes de uma escolha que venha a revelar-se "incorreta" para o mercado - no entanto, reduz também a probabilidade de ganhos maiores; d) a diversificação do portfolio entre moeda (sem risco de renda nominal) e ativos que oferecem retorno reduz o grau de exposição a riscos do investidor (Tobin, 1958), mas, tal como o comportamento convencional, reduz também suas possibilidades de retorno; e) no limite, em estado de forte incerteza, a total rejeição aos ativos não monetários torna-se a mais eficiente proteção individual contra os riscos de um futuro muito incerto - isto caracteriza o que Keynes chamou de "armadilha da liquidez", na qual, de fato, os riscos de renda nominal são eliminados, mas o retorno nominal também.

Em suma, a incerteza típica do mercado financeiro não é um defeito intratável, mas não pode também ser facilmente convertida em "almoço grátis". Os recursos desenvolvidos para contorná-la têm eficácia limitada, o que mantém a condição de ineficiência do mercado, mesmo no plano microeconômico. Mais que isso, as tentativas individuais de proteção, acabam por tornar-se fontes de ineficiência macroeconômica. 
A preferência por liquidez era, na visão de Keynes, a principal fonte de ineficiência macroeconômica na alocação de recursos, tanto no mercado de ativos, onde cria uma tendência curto-prazista que dificulta (e encarece) o financiamento dos investimentos, quanto no mercado de bens, sendo, neste último, a principal causa das recessões. Os contratos podem também gerar ineficiência. Os termos de contratos de dívida assinados em períodos de maior otimismo dos devedores podem se tornar um peso excessivo se, por conta de uma retração econômica inesperada, suas expectativas não se confirmam. O apoio das operações financeiras em expectativas guiadas, em parte, por fatores subjetivos (como o otimismo ou grau de confiança), cuja confirmação depende do comportamento de variáveis desconhecidas e fora do controle do devedor, é a essência da hipótese de fragilidade financeira de Minsky (1982), segundo a qual o mercado financeiro é, inerentemente, frágil e sujeito a crises financeiras - um óbvio fator de ineficiência macroeconômica.

A existência de mercados secundários, aliada à racionalidade do comportamento convencional, da mesma forma, pode conduzir o mercado a uma situação de crise de liquidez e de crédito em períodos de forte incerteza. O "comportamento de manada", que detona crises financeiras ou bolhas especulativas nada mais é do que a manifestação do comportamento convencional em mercados secundários de ativos marcados por forte incerteza.

Em suma, sendo a incerteza uma característica regular das economias de mercado, suas consequências também o são. Isto justifica, no enfoque pós-keynesiano, uma atuação sistemática do Estado no mercado financeiro, visando: a) reduzir a instabilidade macroeconômica, de modo a reduzir o grau de incerteza que afeta o mercado; b) manter sob controle o grau de fragilidade financeira com que opera o mercado; c) conter e, idealmente, compensar a tendência curto-prazista do mercado, de modo a ampliar a disponibilidade de crédito para atividades cujos ativos sejam, em regra, identificados (pelas instituições financeiras e poupadores privados) como ativos de baixa liquidez, por conta de retornos e riscos muito incertos - basicamente, aqueles mesmos setores, antes mencionados, como mais propensos a sofrerem racionamento de crédito.

Quanto ao primeiro desses objetivos, políticas macroeconômicas voltadas para uma combinação "razoável” de crescimento com estabilidade monetária podem ser eficazes; no que tange ao segundo, uma combinação de regulamentação prudencial (restrições) e política financeira (incentivos) pode ser suficiente; quanto ao terceiro, contudo, a atuação direta do governo, com base na criação de um BP pode ser inevitável. Essa questão é analisada com mais detalhe a seguir.

\section{BANCOS PÚBLICOS COMO FORMA DE ATUAÇÃO DO ESTADO NO MERCADO FINANCEIRO}

No modelo Shaw-McKinnon, as formas aceitas de atuação estatal no mercado financeiro são, todas, indiretas, não cabendo sequer o uso do termo "intervenção". São elas: a) supervisão (mas não necessariamente a regulamentação) do setor; b) 
manutenção de um sistema jurídico eficiente, entendido como aquele que assegure o direito de propriedade e o cumprimento dos contratos; c) manutenção dos fundamentos macroeconômicos em equilíbrio (especialmente estabilidade monetária e cambial).

O foco da atuação do Estado no mercado financeiro seria, assim, a segurança do poupador, através da redução dos riscos, e não, diretamente, a melhoria das condições de acesso (volumes e custos) a financiamentos. Esse benefício, em tese, seria obtido como efeito colateral: a proteção dos interesses dos potenciais credores é vista como condição necessária e suficiente para gerar uma oferta adequada de crédito, em suas diversas modalidades:

Uma das principais diferenças entre mercados financeiros desenvolvidos e não desenvolvidos é o papel desempenhado pelos direitos de propriedade. Esses são cruciais para explorar os benefícios do uso de garantias em contratos financeiros. [...] Instituições mais fortes, que protejam os credores, também facilitam o acesso de pequenas empresas ao crédito e aprofundam os mercados hipotecários. Em suma, a existência de melhores instituições não só aumenta o tamanho do bolo, como também permite que mais atores tenham acesso a ele. (BID, 2005, p. 24).

As abordagens de filiação keynesiana fornecem argumentos para justificar a atuação do Estado no mercado financeiro sob variadas formas, desde a supervisão até a criação de BPs. Nesses enfoques, porém, ao contrário da visão liberalizante, na qual a supervisão destina-se a garantir o respeito às regras livremente pactuadas no mercado, a supervisão é vista como complemento da regulamentação financeira: "Once regulations are put in place, governments must monitor banks to ensure compliance" (Stiglitz, 1994, p. 33).

Quanto às demais formas de atuação do governo, grosso modo, pode-se distinguir dois tipos de objetivos: a) reduzir a níveis "inofensivos" as falhas de mercado e a incerteza, bem como seus efeitos financeiros e macroeconômicos; b) compensar estes efeitos, nos casos em que não é possível remover ou atenuar as falhas de mercado e incertezas que lhes dão origem.

No primeiro grupo enquadram-se todas as formas de regulamentação da atividade financeira baseadas na imposição de limites à livre escolha das instituições financeiras quanto à alocação e aos custos dos recursos que administram. Nessa linha de atuação, justifica-se, além de medidas de regulamentação prudencial, voltadas para a redução do risco sistêmico, também algumas medidas de intervenção mais direta, tais como: a) imposição de limites para os juros de operações específicas - como a proibição de pagamento de juros sobre depósitos à vista, visando ao controle da concorrência bancária por recursos dos poupadores e do risco moral envolvido; b) incentivos ou desincentivos tributários a determinados tipos de operação; c) programas de crédito direcionado a setores selecionados, operados por instituições financeiras privadas, com recursos privados, mas com regras definidas 
pelo regulador financeiro - "Programs $[. .$.$] attempt to intervene in the way that$ [private] banks allocate credit [...]" (Stiglitz, 1994, p. 42).

No segundo grupo de objetivos (atuação compensatória), enquadram-se propostas de caráter mais intervencionista, como políticas de crédito direcionado, apoiado em recursos públicos e a criação de BPs. Neste aspecto, porém, há uma diferença importante entre as proposições baseadas nos modelos novo- e pós-keynesiano. $\mathrm{O}$ primeiro mostra-se mais otimista quanto à capacidade daquelas medidas "corretivas" reduzirem significativamente as ineficiências do mercado financeiro e suas consequências macroeconômicas. Nos trabalhos de J. Stiglitz, por exemplo, um dos mais renomados formuladores dessa interpretação, BPs não figuram como formas de atuação recomendadas. ${ }^{8}$ Como Economista-Chefe do Banco Mundial, o autor assumiu clara preferência pelo que chamou de "moderada restrição financeira", em oposição à atuação direta do governo:

"The basic principle of mild financial restraint is that [contrary to financial repression] the government does not extract rents from, but creates rents within, the private sector. The purpose of these rents is to create incentives for the private sector to undertake socially beneficial actions (prudential lending). It is the opposite the government-directed approach where the government undertake these actions itself." (Stiglitz, 1998, p. 9)

Ainda assim, é possível justificar a atuação de BPs com base no modelo de racionamento de crédito. Políticas de incentivo ao crédito para grupos racionados, que, normalmente, assumem a forma de alívio tributário e/ou de exigências regulatórias, visando o aumento das taxas de retorno, terão pouca eficácia: se o que limita ao interesse dos bancos em determinados setores ou tipos de operação é sua baixa ou insuficiente propensão a riscos específicos (assistemáticos), motivada pela atribuição (correta ou não) de elevada probabilidade de insucesso (perdas) na operação, o aumento dos retornos prometidos em caso de sucesso não será um incentivo suficiente, porque não altera as probabilidades estimadas de perda.

Com argumentos semelhantes justifica-se, a partir do enfoque pós-keynesiano, a atuação regular de BPs como meio de ampliar a eficiência macroeconômica do mercado financeiro. As demais formas de atuação, embora possam minorar algumas ineficiências naturais do mercado, têm em comum a limitação de serem nãocoercitivas, atuando por indução. Para que este tipo de política possa estimular as operações marcadas por maior incerteza, deve ser capaz de gerar um conjunto de informações que delimite, de forma razoavelmente clara e segura, as probabilidades de retorno e risco dessas operações. Mais que isso, é necessário garantir que tais

\footnotetext{
${ }^{8}$ Stiglitz reconhece a existência de BPs em países em desenvolvimento, mas não chega a recomendá-los: “[...] In some instances, the government takes primary responsibility for creating new financial institutions or institutional arrangements; in others, it takes actions that make the establishment of certain financial institutions viable or more likely" (Stiglitz, 1994, p. 32).
} 
probabilidades se situem em intervalos favoráveis (altas para os retornos e baixas para os riscos).

Sendo, porém, o governo tão sujeito quanto os agentes privados às limitações informacionais decorrentes da incerteza, ele não estará em posição de garantir essas condições. Nestes casos, portanto, a única forma de compensar a incompletude do mercado nos setores mais afetados pela incerteza é o governo assumir, diretamente, os riscos que o setor privado rejeita. Neste enfoque, uma das principais funções de um BP é, justamente, a assunção de riscos em setores com importantes externalidades positivas para o processo de desenvolvimento econômico. É da natureza desse processo a necessidade de investimentos em setores, produtos e/ou processos produtivos novos; de grande volume de investimentos de longo prazo; e de mudanças estruturais (via incorporação de inovações e/ou ampliação da oferta de infraestrutura). Essas condições tornam o desenvolvimento econômico um processo marcado por grande incerteza e elevado custo - embora possa também envolver elevada taxa de retorno. No entanto, é da natureza do mercado financeiro a rejeição a ativos de retorno muito incerto. A incerteza que marca, mais fortemente, alguns tipos de operação, é vista, no enfoque pós-keyensiano, como o principal entrave à completude do mercado financeiro.

Essa combinação de coisas cria duas grandes dificuldades financeiras para o desenvolvimento econômico: a) risco de fragilização financeira; b) escassez de crédito de longo prazo.

O risco de fragilização financeira é inerente a qualquer operação de endividamento (Minsky, 1982), mas torna-se mais elevado quanto maior o descasamento de prazos entre o ativo e o passivo do devedor (porque aumenta seu risco de liquidez e, por conseguinte, o risco de crédito do credor) e quanto mais longo o prazo dos contratos (porque isto torna mais difícil a avaliação de riscos em geral). O descasamento de prazos é uma situação bastante provável (e comum, na prática) em operações de financiamento de investimentos de longo prazo. Isto se dá porque, diante do maior risco, normalmente, atribuído a tais operações, suas taxas de juros tendem a ser maiores que as de curto prazo - ou seja, a "curva de rendimentos" é, normalmente, ascendente. Essas condições induzem o investidor (tomador de crédito) mais otimista a assumir o que Minsky chamou de "postura especulativa": o financiamento de longo prazo é montado a partir de operações de prazos mais curtos, que (especula-se) serão sucessivamente renovadas (não necessariamente com o mesmo credor), até que se complete o prazo de maturação do investimento. Esse modelo de financiamento facilita o acesso a crédito, inclusive a custos provavelmente mais baixos, mas, a cada renovação, envolve o risco de uma mudança desfavorável nas condições do mercado.

A escassez e/ou alto custo do crédito de longo prazo é um desestímulo à própria demanda e, portanto, aos investimentos em geral, tornando-se, assim, um entrave ao desenvolvimento econômico. Isto justifica a atuação de um BP como provedor direto de fundos para setores estratégicos para o desenvolvimento, que eventualmente ou regularmente sejam preteridos pelo mercado. Para tanto, basta que o banco seja capaz de disponibilizar, de forma regular, linhas de financiamento de 
longo prazo, a custos mais baixos (mas não necessariamente subsidiados) que os exigidos pelas instituições privadas (caso entrassem neste mercado). Isto é possível porque o BP, idealmente, não embute em suas taxas de juros o mesmo grau de risco do setor privado. Três razões justificam tal procedimento: a) a própria disponibilidade de crédito de longo prazo reduz o risco de liquidez do devedor; b) o BP teria como parte de sua "missão" a função de assumir alguns tipos de riscos rejeitados pelas instituições privadas; c) o BP, idealmente, não define suas taxas de juros com base em metas de lucro, mas sim de equilíbrio financeiro, que exige apenas o controle do descasamento de prazos e valores entre os fluxos de receita e despesa, de modo a manter baixos os riscos de juros, de liquidez e de insolvência.

Outra condição que justifica a atuação de um BP, especialmente nos países em desenvolvimento, é a necessidade de autonomia financeira para a implementação de políticas de desenvolvimento. Isto pode ser feito, em parte, com base em investimentos públicos, financiados com impostos e/ou dívida pública. No entanto, essa estratégia é limitada pela restrição orçamentária do governo, cujos recursos sofrem ingerências políticas e legais e são disputados por um elenco variado de rubricas. Ainda que se formule um orçamento de capital separado do orçamento corrente (de consumo), as necessidades de custeio e as obrigações financeiras do governo, que são despesas inelásticas a curto prazo, serão, sempre, um limite potencial à alocação desses recursos a políticas de desenvolvimento.

A autonomia financeira dos BPs tende a ser maior que a do governo devido à possibilidade do primeiro recorrer a fontes de funding mais diversificadas, entre elas: a captação de poupança doméstica (voluntária ou compulsória), empréstimos de outros bancos (nacionais ou estrangeiros) e, principalmente, o reinvestimento do excedente operacional. Além disso, nos BPs, a concorrência por despesas alternativas é menor, já que estes, idealmente, são focados no financiamento de investimentos, e não de consumo.

Por fim, vale notar que o funding mais diversificado dos BPs, quando comparado às fontes típicas de financiamento do Tesouro Nacional, é, socialmente, mais justo que o apoio em impostos e dívida pública. Nesses casos, o ônus do financiamento recai sobre toda (ou grande parte) da sociedade, e não apenas sobre agentes com alguma capacidade de poupança. Assim, mesmo na presença de um sistema tributário adequadamente progressivo, a combinação de investimentos públicos "convencionais" com a atuação de um BP tende a produzir uma melhor alocação de recursos que a concentração da política de desenvolvimento no orçamento fiscal do governo.

\section{NOTAS CONCLUSIVAS: O PAPEL (E O FUTURO) DOS BANCOS PÚBLICOS EM SISTEMAS FINANCEIROS MADUROS}

Este artigo analisou duas visões alternativas sobre o papel dos BPs nos sistemas financeiros. No modelo Shaw-McKinnon os BPs ainda existentes nos países em desenvolvimento estariam com os “dias contados”, em face da inegável expansão 
e diversificação de seus sistemas financeiros a partir dos anos 1990. A iminente “completude" desses mercados eliminaria, gradualmente, a necessidade de atuação de BPs, restando apenas a função supervisora do governo.

No enfoque keynesiano esse cenário é considerado pouco plausível. Neste, a incompletude dos mercados financeiros não é explicada por fatores externos (políticas financeiras inadequadas), mas sim por condições inerentes ao modo normal de operação do mercado financeiro e ao processo de desenvolvimento econômico. $\mathrm{O}$ mercado financeiro é visto como intrinsecamente ineficiente do ponto de vista macroeconômico, seja porque tende a racionar crédito para setores importantes para o desenvolvimento ou porque, em momentos de maior otimismo, tende a expandir o crédito (não necessariamente para aqueles setores) de forma pouco cautelosa, aumentando a fragilidade financeira a que se expõe a economia. Essa condição, por si só, justifica uma atuação regular do Estado no mercado financeiro, não só através de regulamentação e políticas de incentivo, mas também através de BPs.

$\mathrm{Na}$ perspectiva pós-keynesiana, dificilmente o desenvolvimento do sistema financeiro representará uma ameaça letal para os BPs. Diante daqueles fatores intrínsecos de ineficiência, por mais desenvolvidos e diversificados que se tornem os sistemas financeiros, uma situação de "completude" dos mercados jamais será alcançada, mesmo nos países mais desenvolvidos. Este cenário mostra-se ainda menos provável nos países em desenvolvimento.

A relação entre desenvolvimento econômico e financeiro é fartamente tratada na literatura especializada e há hoje amplo consenso em torno da ideia de que ambos são fenômenos mutuamente condicionados e caracterizados por path dependence, isto é, cuja trajetória se define, em grande parte, pelo estado vigente no ponto de partida. ${ }^{9}$ Quanto mais avançado o processo de desenvolvimento econômico, maiores são os níveis de renda agregada e per capita da economia. Admitindo-se que a maior renda per capita contribua para tornar os poupadores menos avessos a riscos, tal condição tende a favorecer a alocação da poupança a ativos de médio e longo prazo. Assim, o desenvolvimento econômico favorece a expansão e diversificação do mercado financeiro e, através deste, a sua própria continuidade, gerando um círculo virtuoso entre os dois processos.

Analogamente, pode-se esperar que um baixo grau de desenvolvimento econômico dificulte o desenvolvimento financeiro, e vice-versa. Isto explica que as incompletudes do mercado financeiro nos países em desenvolvimento sejam, em geral, mais graves e restritivas que nos países mais desenvolvidos, o que reforça a necessidade de atuação de BPs nos primeiros.

Contudo, à medida que o sistema financeiro nacional se expande e diversifica, altera-se seu grau de incompletude, bem como os segmentos do mercado mais atingidos. Assim, o desenvolvimento econômico e financeiro exigirá dos BPs a definição de novas estratégias de operação, um tanto distintas daquelas que lhes deram origem. Cabe, assim, concluir estas notas com uma lista preliminar e espe-

\footnotetext{
${ }^{9}$ Para um survey dessa discussão ver o já citado Levine (2004).
} 
culativa de possíveis tendências de mudança nas formas de atuação dos BPs em países com sistemas financeiros gradativamente mais maduros:

a) Os antigos setores "nascentes", apoiados pelos BPs, tornam-se "maduros". Em países com sistemas financeiros também maduros, tal ascensão, gradativamente, credencia esses setores como focos de interesse das instituições privadas (aí incluído o mercado de capitais).

b) É possível que os BPs assistam a uma queda na demanda por seus serviços, especialmente, por parte das empresas de maior porte e boa reputação no mercado, que passarão a ser disputadas pelos investidores privados (inclusive externos). Aos BPs caberão, principalmente, ativos preteridos pelo mercado, inclusive dos novos setores líderes do desenvolvimento no período.

c) O balanço dos BPs, portanto, tende a tornar-se mais concentrado em ativos de mais difícil avaliação de riscos - embora, não necessariamente, de risco mais elevado - que são os mais restringidos pelo sistema financeiro privado, mesmo nos países com grau razoável de desenvolvimento financeiro.

d) Com isto, tende a elevar-se o risco de crédito a que se expõem os BPs. Tal efeito, provavelmente, tornará necessário rever os modelos e estratégias de administração de riscos do banco.

e) Considerando que a implementação de mudanças na gestão de riscos pode ser custosa e lenta e que não existem instrumentos de hedge "perfeitos", é necessário que as potenciais mudanças na estrutura ativa dos BPs sejam implementadas de forma cautelosa. A manutenção de empresas e/ou setores de boa qualidade de risco na carteira dos BPs, ainda que estes possam ser atendidos pelo mercado privado, pode ser indicada, não apenas como meio de adaptação do banco às novas condições do mercado, mas como instrumento regular de defesa da qualidade do risco de seu ativo.

\section{REFERÊNCIAS BIBLIOGRÁFICAS}

AGÉNOR, P. e MONTIEL, P. J. (1999). Development Macroeconomics. $2^{\text {nd }}$ ed. New Jersey: Princeton University Press.

BNDES - Banco Nacional de Desenvolvimento Econômico e Social (2007). O Novo Acordo da Basileia e suas Implicações para o BNDES. $2^{\circ}$ Relatório Parcial, Cap. 1 . Rio de Janeiro, BNDES.

BID - Banco Interamericano de Desenvolvimento (2005). Libertar o Crédito: como aprofundar e estabilizar o financiamento bancário. Rio de Janeiro: Campus.

DIXON, H. (1997). “Controversy: Finance and Development (Editorial Note)". The Economic Journal, Vol. 107, May, pp. 752-753.

GOODHART, C. A. E. (1989). Money, Information and Uncertainty. $2^{\text {nd }}$ ed. London: MacMillan Press.

GURLEY, J. e SHAW, E. (1955). "Financial aspects of economic development". American Economic Review, Vol. XLV, ${ }^{\circ}$ 4, September, pp. 515-538.

HERMANN, J. (2000). "O Modelo de Racionamento de Crédito e a Política Monetária Novo-Keynesiana: uma análise crítica”. Revista de Economia Política, Vol. 20, $\mathrm{n}^{\circ} 2$ (78), abril-junho, pp. 53-75.

HERMANN, J. (2003). “O modelo de liberalização financeira dos anos 1990: 'restatement' ou autocrítica?”. Revista Nova Economia (UFMG), Vol. 13, n 2, julho-dezembro, pp. 137-172. 
HERMANN, J. (2009). “Liberalização e desenvolvimento financeiro: lições da experiência brasileira no período 1990-2006". Revista Economia e Sociedade (no prelo).

KEYNES, J. M. (1985/1936). A Teoria Geral do Emprego, do Juro e da Moeda. São Paulo: Abril Cultural. Publicação original: The General Theory of Employment, Interest and Money. London: MacMillan.

KREGEL, J. (1980). "Markets and Institutions as Features of a Capitalistic Production System". Journal of Post Keynesian Economics, Fall, Vol. 3, n 1, pp. 32-48.

LEVINE, Ross (1997). "Financial development and economic growth: Views and agenda". Journal of Economic Literature, Vol. XXXV, June, pp. 688-726.

LEVINE, Ross (2004). "Finance and growth: theory and evidence". Paper prepared for the Handbook of Economic Growth. Carlson School of Management, University of Minnesota and the NBER.

MCKINNON, R. (1973). Money and Capital in Economic Development. Brookings Institution.

MINSKY, P. H. (1982). "The financial fragility hypothesis: An interpretation of Keynes and an alternative to 'Standard' Theory", in H. P. Minsky, Can It Happen Again? Essays on Stability and Finance. New York: M. E. Sharpe, Inc, pp. 59-70.

PANIZZA, U., YEYATI, E. L. e MICCO, A. (2004). "Should the government be in the banking business? The role of state-owned and development banks". Working Paper 517, Inter-American Development Bank (BID), Research Department.

ROSS, S. (1994). "Finance”, in P. Newman, M. Milgate e J. Eatwel (Ed.). The New Palgrave Dictionary of Money and Finance, Vol 3. London: MacMillan Press, pp. 26-41.

SHAW, E. S. (1973). Financial Deepening in Economic Development. New York: Oxford University.

STIGLITZ, G. (1994). “The role of the state in financial markets". Proceedings of the World Bank Annual Conference on Development Economics 1993.

STIGLITZ, G. (1998). "The role of the financial system in development.” The World Bank Group, Presentation at the Fourth Annual Bank Conference on development in Latin America and the Caribbean (LAC-ABCDE). The World Bank, via Internet: www.worldbank.org.

STIGLITZ, J. E. e WALSH, C. E. (2003). Introdução à Microeconomia. $3^{\mathrm{a}}$ ed. Rio de Janeiro: Campus.

STIGLITZ, J. e WEISS, A. (1981). “Credit rationing in markets with imperfect information”. American Economic Review, 71, June, pp. 353-376.

STUDART, R. (1995-96). "The efficiency of financial system, liberalisation and economic development”. Journal of Post-Keynesian Economics, 18 (2), Winter, pp. 265-289.

TOBIN, J. (1958). "Liquidity preference as behavior toward risk". The Review of Economic Studies, Vol. $25, \mathrm{n}^{\circ}$ 2, February, pp. 65-86.

TOBIN, J. (1994). "Financial intermediaries”, in P. Newman, M. Milgate e J. Eatwel (Ed.). The New Palgrave Dictionary of Money and Finance, Vol 1. London: MacMillan Press, pp. 77-85.

Zysman, J. (1983). Governments, Markets and Growth. London: Cornell University Press. 